\title{
Article \\ Effects of In Situ Graphitic Nanocarbon Coatings on Cycling Performance of Silicon-Flake-Based Anode of Lithium Ion Battery
}

\author{
Yonhua Tzeng *D, Wei-Chih Huang, Cheng-Ying Jhan and Yi-Hsuan Wu
}

Citation: Tzeng, Y.; Huang, W.-C.; Jhan, C.-Y.; Wu, Y.-H. Effects of In Situ Graphitic Nanocarbon Coatings on Cycling Performance of Silicon-Flake-Based Anode of Lithium Ion Battery. Coatings 2021, 11 138. https://doi.org/10.3390/ coatings11020138

Academic Editors: Torsten Brezesinski and Je Moon Yun Received: 19 November 2020 Accepted: 21 January 2021 Published: 27 January 2021

Publisher's Note: MDPI stays neutral with regard to jurisdictional claims in published maps and institutional affiliations.

Copyright: (c) 2021 by the authors. Licensee MDPI, Basel, Switzerland. This article is an open access article distributed under the terms and conditions of the Creative Commons Attribution (CC BY) license (https:// creativecommons.org/licenses/by/ $4.0 /)$.
Department of Electrical Engineering, Institute of Microelectronics, National Cheng Kung University, One University Road, Tainan 70101, Taiwan; michae128619551@gmail.com (W.-C.H.); m10506126@gmail.com (C.-Y.J.); d980372@gmail.com (Y.-H.W.)

* Correspondence: tzengyo@mail.ncku.edu.tw

\begin{abstract}
We coated graphitic nanocarbons by thermal chemical vapor deposition (CVD) on silicon flakes recycled from the waste of silicon wafer manufacturing processes as an active material for the anode of lithium ion battery (LIB). Ferrocene contains both iron catalyst and carbon, while camphor serves as an additional carbon source. Water vapor promotes catalytic growth of nanocarbons, including carbon nanotubes (CNTs), carbon fibers (CFs), and carbon films made of graphitic carbon nanoparticles, at temperatures ranging from 650 to $850{ }^{\circ} \mathrm{C}$. The container of silicon flakes rotates for uniform coatings on silicon flakes of about $100 \mathrm{~nm}$ thick and 800-1000 nm in lateral dimensions. Due to short CVD time, besides CNTs and CFs, surfaces of silicon flakes deposit with high-density graphitic nanoparticles, especially at a low temperature of $650{ }^{\circ} \mathrm{C}$. Nanocarbon coatings were characterized by SEM, EDX, ESCA, and Raman spectroscopy. Half-cells were characterized by cyclic voltammetry (CV), electrochemical impedance spectroscopy (EIS), and retention of capacity in discharge/charge cycling. Silicon-flake-based anode with nanocarbon coatings at both 650 and $850{ }^{\circ} \mathrm{C}$ exhibited capacity retention of $2000 \mathrm{mAh} / \mathrm{g}$ after 100 cycles at $0.1 \mathrm{C}$, without needing any conductivity enhancement material such as Super P.
\end{abstract}

Keywords: LIB; silicon; silicon oxide; CNT; CF; nanocarbon; anode

\section{Introduction}

The lithium ion battery (LIB) is characterized as having high potential, energy density, and power and being capable of having a long cycling life for repetitive charging and discharging in a wide temperature range. The commonly used anode material for LIB is graphite, which has a theoretical capacity of $372 \mathrm{mAh} / \mathrm{g}$. The capacity of graphite does not meet the high demands by long-range electric vehicles (EVs) and large-scale storage of intermittent renewable energy [1-3]. Silicon provides some hope for greatly increased capacity of LIB anode because its theoretical capacity of $4200 \mathrm{mAh} / \mathrm{g}$ is more than ten times of that for graphite [4]. Besides this, silicon is widely used in the semiconductor industry and is abundant and inexpensive. Unlike delithiation and lithiation of graphite anode during charge and discharge cycling, lithium forms alloys with silicon during discharging. The alloys dissociate to release lithium during charging. The discharge potential for silicon is low. It is inert to solvent co-intercalation [5,6]. However, the alloying reactions and the subsequent dissociation of alloys result in as high as $420 \%$ volume changes of silicon [7].

Silicon has large volume change on cycling. Brittle silicon might crack. Crack surfaces yield fresh solid-electrolyte interphase (SEI). SEI creation consumes lithium irreversibly. Irreversible lithium consumption makes the battery fail prematurely [8,9].

An ideal electrolyte is an ionic conductor but electronic insulator. When an electrolyte is unstable in the presence of the anode active material, electrons transfer from the active material to the electrolyte causes the electrolyte to decompose by reduction. This process 
produces a compound on the surface of the active material and consume lithium. This compound is a solid-state electrolyte, which is conductive for lithium ions but an insulator for electrons. The compound is known as solid-electrolyte interphase (SEI). A stable SEI prevents the electrolyte from further decomposition because the SEI is electrically insulating and electrons cannot transport through SEI from the active material to the electrolyte to cause more reduction of the electrolyte. If the SEI is not perfect, reduction of electrolyte continues and the SEI grows thicker. When an active material particle breaks apart to expose fresh surface, new SEI layer will form on fresh surface by the same process and more lithium is consumed [4,10-12]. SEI is a compound containing lithium. Therefore, the formation of irreversible SEI consumes the limited amount of lithium in a packaged LIB. If the consumption of lithium continues and the lithium is exhausted, the LIB fails prematurely.

For a pulverized silicon particle, new SEI forms on the freshly exposed surface of individual fine particles of silicon. The electrical connection between fine particles of a pulverized silicon particle is also lost and electron transports to and from the fine particles are terminated. The capability of alloying and dissociation of alloys is lost, i.e., these fine silicon particles cease to contribute to the capacity of the anode. The pulverized silicon particle also exposes a much larger effective silicon surface area to the electrolyte. A much larger SEI layer will form at the expense of the limited supply of lithium within the LIB.

Therefore, two main challenges for a silicon-based LIB anode are (i) to prevent silicon particles from breaking apart or even pulverize and (ii) to prevent broken pieces of silicon from losing electrical connections with the current collector and reacting with the electrolyte to form new SEI. Many efforts were made to avoid or minimize the pulverization of silicon in a silicon anode. If pulverization occurs, smaller break-apart silicon particles must retain their electrical connections with the current collector of a LIB and be isolated from exposing and reacting with the electrolyte to form additional SEI. In short, maintaining the physical integrity of silicon-based anode of LIB is the top priority.

Nanostructured silicon and nanoscale silicon particles [13-15] with critical dimensions about sub-100 nm, especially in the low tens of nanometers, are promising candidates because, unlike bulk silicon atoms, lithium-silicon alloys on the surface of a silicon particle can expand outwards in volume freely. The smaller a particle is the higher the ratio of the number of surface atoms to that of bulk atoms will be. These nanoscale silicon particles and structures include, for example, zero-dimensional nanoparticles, one-dimensional nanowires and nanotubes, two-dimensional nanoscale films, and three-dimensional porous structures [16-23].

However, both top-down manufacturing and bottom-up synthesis of nanoscale silicon particles and structures are expensive. A compromise solution for achieving durable and high capacity by as economic as possible manufacturing methods of LIB anodes are being pursued by technologists around the world. Graphite has been a very stable anode material for traditional LIBs. It is natural that carbon-based nanostructures are desirable coatings for anode materials for LIBs [24]. Silicon-carbon composites are, therefore, considered promising for resolving the challenging issues of silicon-based anode. Graphene and graphene oxide mix with and wrap around silicon nanoparticles $[25,26]$. Carbon nanotubes (CNTs) mix with silicon particles, to fill voids between silicon nanoparticles as additional electrical connections $[27,28]$. Pyrolysis of polymeric coatings on silicon nanoparticles forms solid or porous carbon interfacial layers $[29,30]$. Synthesis of graphene nanowalls directly and vertically on the silicon surface, after removing native oxide, provides both a carbon interfacial layer and outward extending graphene as extra electrical interconnections [20]. The thermal CVD of nanocarbon films and CNT has also been studied [31-33]. An ideal carbon interfacial layer is to provide excellent electrical conductivity, provide necessary buffer space for the volume expansion of silicon, and isolate the fresh surface of pulverized silicon from reactions with electrolyte, to form additional SEI. The optimal carbon interfacial layer needs to be able to be mass-manufactured economically. 
We report the effects of in situ thermal CVD of graphitic nanocarbon coatings, including CNT-like and carbon-fiber-like one-dimensional nanocarbon nanostructures on silicon flakes, on sustainable cycling performance and improved retention of capacity of silicon-based anode. Many research groups around the world have reported a wide variety of methods of depositing CNT [34,35]. We used inexpensive silicon flakes of approximately $100 \mathrm{~nm}$ in thickness and 800-1000 $\mathrm{nm}$ in length, supplied by one of our industrial collaborators in Taiwan. The company produces a large quantity of waste slurry containing flake-shaped silicon from cutting and processing silicon ingots and wafers. Proprietary methods were applied to purify silicon flakes extracted from the waste.

\section{Materials and Methods}

Silicon flakes of about $100 \mathrm{~nm}$ thick and 800-1000 nm long and wide were acquired from AUO Crystal, Inc., which is a silicon wafer manufacturing company. It is part of silicon-containing waste slurry generated by cutting silicon ingots and other wafer manufacturing processes. The company uses an economic proprietary chemical process to recover the silicon flakes from the slurry. The industrial supplier did not specify the doping types and concentrations.

Figure 1 shows a schematic diagram of the thermal CVD system, which is used for the deposition of conductive graphitic nanocarbons on silicon anode materials. There are two heating zones, with temperatures separately controlled by electronic temperature controllers. Inside the heating zone 1 are ferrocene and camphor. Figure 2 shows the molecular structures of ferrocene and camphor. Ferrocene contains iron, which serves as a catalyst for the deposition of graphitic nanocarbons and one-dimensional CNTs and CFs [36-38]. Without an effective catalyst, amorphous carbon usually deposits under similar conditions. Ferrocene also serves as a carbon source. Camphor provides additional carbon [39]. Both ferrocene and camphor are heated to $160^{\circ} \mathrm{C}$. Argon carries gas bubbles through water at room temperature, carries water vapor to mix with vapor of ferrocene and camphor in heating zone 1 , and carries the mixed vapor to the heating zone 2 for CVD reactions. The coating process does not involve combustible or explosive gas sources stored in high-pressure cylinders, such as hydrogen and methane.

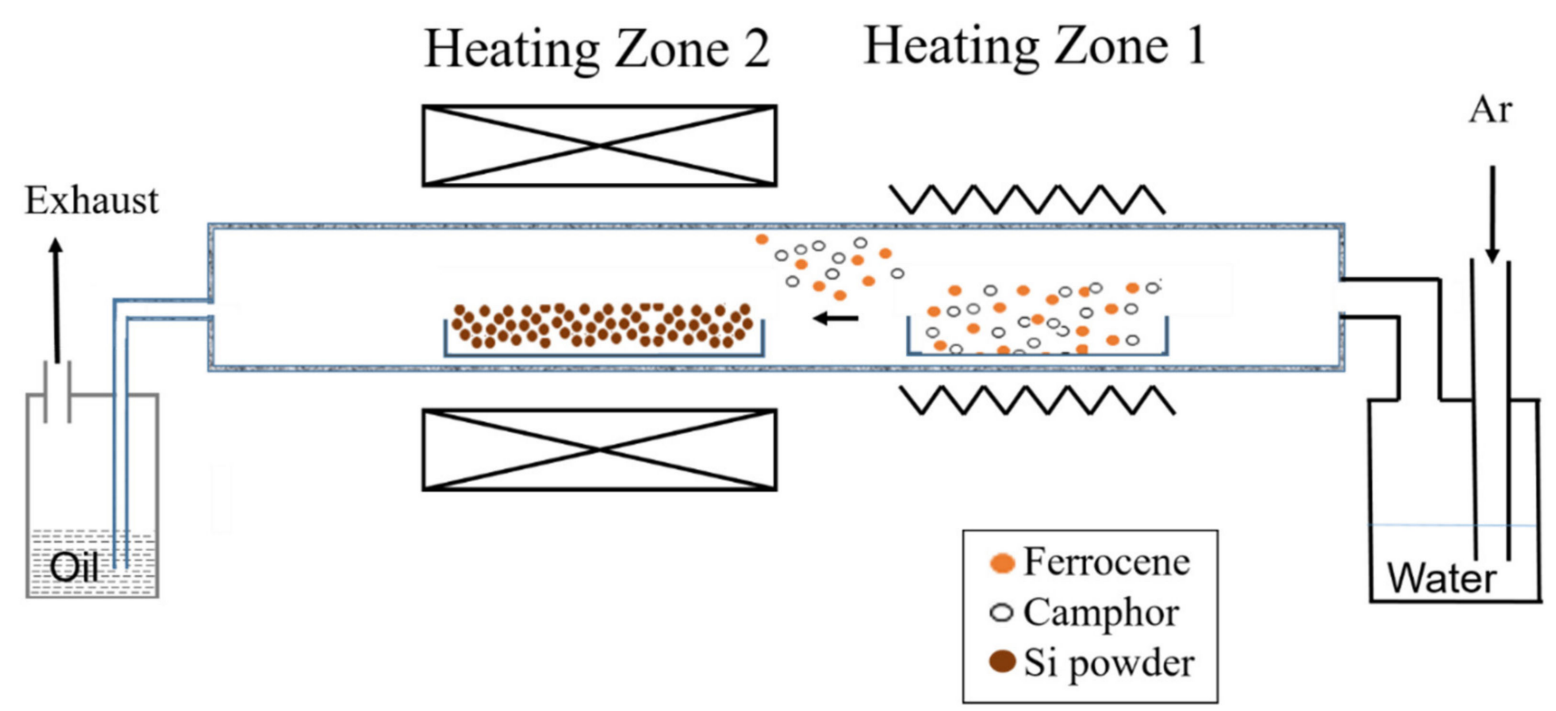

Figure 1. Schematic diagram of a thermal chemical vapor deposition (CVD) system for the deposition of conductive nanocarbons on silicon. 


\section{Carbon Source \\ : Camphor}

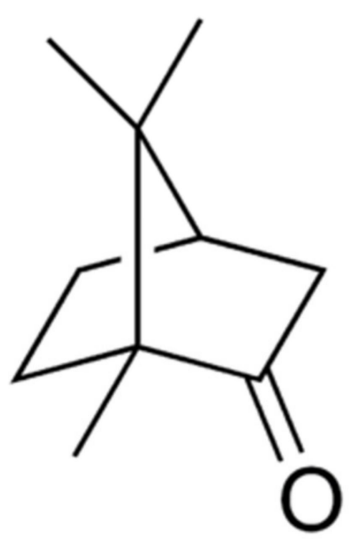

$\mathrm{C}_{10} \mathrm{H}_{16} \mathrm{O}$

\section{Fe Catalyst and Carbon}

Sources : Ferrocene

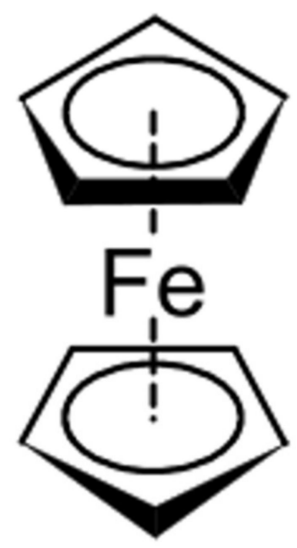

$\mathrm{Fe}\left(\mathrm{C}_{5} \mathrm{H}_{5}\right)_{2}$

Figure 2. Molecular structures of camphor and ferrocene.

Inside the heating zone 2 are silicon flakes. The container for silicon flakes is rotatable along the longitudinal axis of the tube reactor. Deposition of conductive nanocarbons on silicon flakes is uniform by this mechanism (not shown). A mechanical roughing pump (not shown) pumped down the reaction chamber to about 50 mTorr. Argon gas fills the reaction chamber. Argon gas purges the reaction chamber, to reduce the residual gases. The CVD process was at one atmospheric pressure. Since ferrocene and camphor sublimate at a lower temperature than that for the CVD of nanocarbons, ferrocene and camphor were placed in the heating zone 1 . The temperature in zone 1 was high enough for fast sublimation of ferrocene and camphor, even when the heating zone 2 in the down-stream was at the CVD temperature. Heating zone 2 was heated up first to the preset temperature of 650 or $850{ }^{\circ} \mathrm{C}$. The heater for heating zone 1 was then turned on with a preset temperature of $160{ }^{\circ} \mathrm{C}$. At $160{ }^{\circ} \mathrm{C}$, ferrocene and camphor sublimate but do not decompose. The vapor was carried by argon gas from heating zone 1 to heating zone 2, where ferrocene and camphor decompose and deposit CNTs and nanocarbon films on silicon flakes, using iron in ferrocene as a catalyst. The Ar flow rate is $400 \mathrm{sccm}$. An example of precursor loading includes $0.7 \mathrm{~g}$ silicon flakes, $4 \mathrm{~g}$ camphor, and $1.8 \mathrm{~g}$ ferrocene. The growth time was $15 \mathrm{~min}$ for the deposition of nanocarbons of about $10 \%$ by weight in the processed silicon flakes. A bubbler isolates the reaction chamber from the atmosphere.

The morphology and the structure of the nanocarbon-coated silicon flakes were observed by scanning electron microscopy (SEM, Hitachi-SU8000, Taipei, Taiwan). A Horiba Scientific Raman (Hsinchu, Taiwan) system with a green laser at $532 \mathrm{~nm}$ and laser power at $450 \mathrm{~mW}$ was used to measure Raman spectra. The laser beam was focused on the specimen surface in an area of about $10 \mu \mathrm{m}$ in size. Raman spectra reveals the nanostructures of nanocarbons. The Fe catalyst was analyzed by Electron Spectroscopy for Chemical Analysis (ESCA) (PHI 5000 Versa Probe Electron Spectroscopy for Chemical Analysis, Taipei, Taiwan), using crystalline aluminum target at $24.9 \mathrm{~W}$ at an illumination angle of 45 degrees for an exposure area of $100 \mathrm{~m}^{2}$.

Coin cells (CR2032) were fabricated for testing the performance of the anode. Nanocarbonscoated silicon flakes were mixed with Super-P carbon black and sodium carboxymethyl cellulose (NaCMC) in DI water with a weight ratio of $6: 2: 2$ or 8:0:2 corresponding to anodes with Super P additive and that without Super P additive, respectively. Super P 
conductive carbon black of the size of D50 $=20 \mathrm{~nm}$ and surface area of $62 \mathrm{~m}^{2} / \mathrm{g}$ was used as a conducting additive in the anode, to improve the electronic conductivity. The slurry was stirred homogenously and then applied on a $10 \mu \mathrm{m}$ thick copper foil, by a doctor blade. The thickness of the active materials was $30 \mu \mathrm{m}$. After the electrode was dried at $60^{\circ} \mathrm{C}$ for $12 \mathrm{~h}$, the electrode was cut into small pieces with a diameter of $12 \mathrm{~mm}$. The electrode was put into an Ar-filled glove box with less than $0.5 \mathrm{ppm}$ residual oxygen and moisture contents, to assemble the coin cell. The electrolyte was the $1 \mathrm{M} \mathrm{LiPF} 6$ in ethylene carbonate (EC) and dimethyl carbonate (DMC) (1:1 $v / v)$ solution. The charge-discharge cycling performance was analyzed by a battery testing system (BAT-750B). The specific capacity refers to the $\mathrm{mAh}$ per gram of silicon active material in the anode. When a restricted cycling measurement is done, the target specific capacity divided by the charging-discharging rate determines the time of discharging (lithiation) and charging (delithiation). When there is no restriction to the maximum discharging level, the discharging is cut off at the potential of $10 \mathrm{mV}$, and the charging is cut off at the potential of $1.5 \mathrm{~V}$.

During the doctor-blade thick-film fabrication process, silicon flakes compress flexible CNTs and CFs, to minimize the porosity. The effective surface area of CNTs- and CFs-coated silicon flakes synthesized in our project was measured by means of the Brunauer-EmmettTeller (BET) method to be of the order of $50 \mathrm{~m}^{2} / \mathrm{g}$. Because the increased effective surface area of graphitic nanocarbons is electrochemically stable and the capacity is much smaller than that of silicon, it does not cause significant adverse effects to the anode performance. The electrochemical properties, such as cyclic voltammetry $(\mathrm{CV})$, were measured by using Autolab (Metrohm AUTOLAB BV). The CV measurement was carried out at a scanning rate of $0.1 \mathrm{mV} \cdot \mathrm{s}^{-1}$, at room temperature $[19,20,40]$.

\section{Results and Discussion}

\subsection{Thermal CVD of CNTs on Planar Oxidized Silicon Wafers}

Figure 3 shows SEM images of one-dimensional CNT bundles grown at $850{ }^{\circ} \mathrm{C}$, on the surface of an oxidized silicon wafer, under the same conditions to be used for coating nanocarbons on silicon flakes. The CNT density is so high that a forest-like layer of CNTs grew on the substrate, appearing as a bright bottom in the SEM image of Figure 3A. CNTs joined to form the top layer of a CNT forest, as shown at the top image in Figure 3A. Figure $3 \mathrm{~B}$ shows a magnified view of a CNT forest after wiping the substrate with a razor blade. On the substrate, it shows a high density and short CNTs from broken CNTs by the wiping action. Some CNT-bundles in the SEM image of Figure 3B appear to be suspending but are actually supported by their tips, which join together with neighboring CNTs due to the high density of the CNT-forest. Figure $3 \mathrm{C}$ shows a further magnified image of a bundle of CNTS. These results clearly demonstrated that high-density CNTs grew in 15 min under the thermal CVD conditions. Water plays an important role in etching amorphous carbon, which may cover Fe catalyst, for Fe to remain an active catalyst.
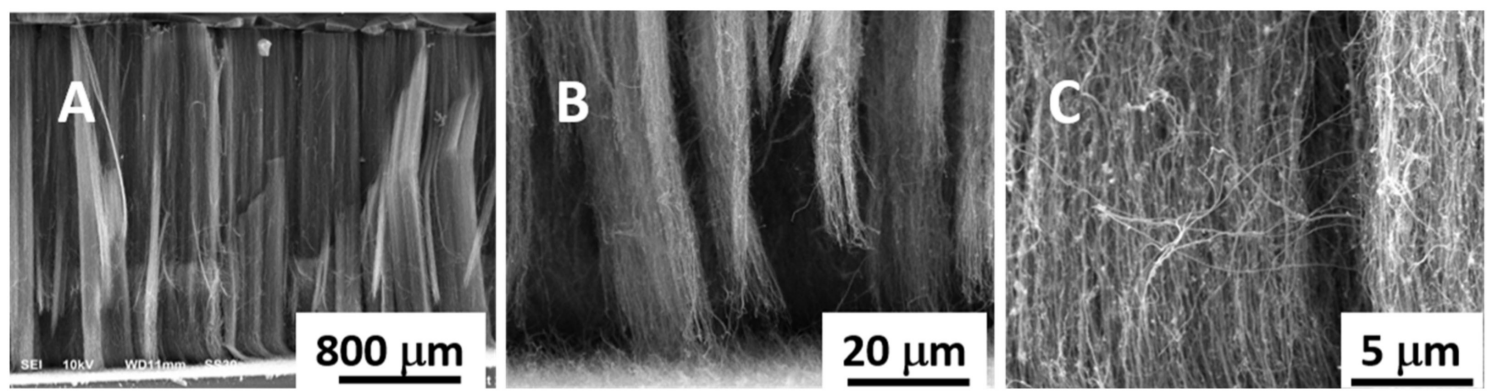

Figure 3. Cross-sectional view of SEM images of one-dimensional carbon nanotubes (CNTs) grown on a silicon wafer under CVD conditions for the nanocarbon coating on silicon flakes at $850{ }^{\circ} \mathrm{C}$. (A) Top-to-bottom cross-sectional view of the CNT forest; (B) CNT bundles near the substrate after having been wiped off by a razor blade; (C) Magnified view of (B). 
Figure 4 shows a Fe 2p ESCA spectrum of CNTs grown on silicon, at $650{ }^{\circ} \mathrm{C}$, under the same conditions used for this work. Peaks at 707.9 and $720.6 \mathrm{eV}$ correspond to metallic Fe. Evidences of oxidized states of Fe are displayed by the peaks at $711.0 \mathrm{eV}$, the shoulder at $714.0 \mathrm{eV}$, and peaks at 724.4 and $727.3 \mathrm{eV}$. The CVD reactor is not of ultra-high vacuum. The water bubbler contains deionized water without degassing. Residual oxygen oxidized Fe in water vapor, at elevated temperature of $650{ }^{\circ} \mathrm{C}$ and above effectively. The major role of water vapor in etching amorphous carbon coatings on the Fe catalyst at the CVD temperature results in the Fe catalyst being active and quickly encapsulated by CNTs and graphitic carbons, which are physically and chemically more durable than amorphous carbon for protecting Fe from exposure to the environments. Metallic Fe nanoparticles encapsulated by CNTs and graphitic carbons do not react with the electrolyte in an LIB.

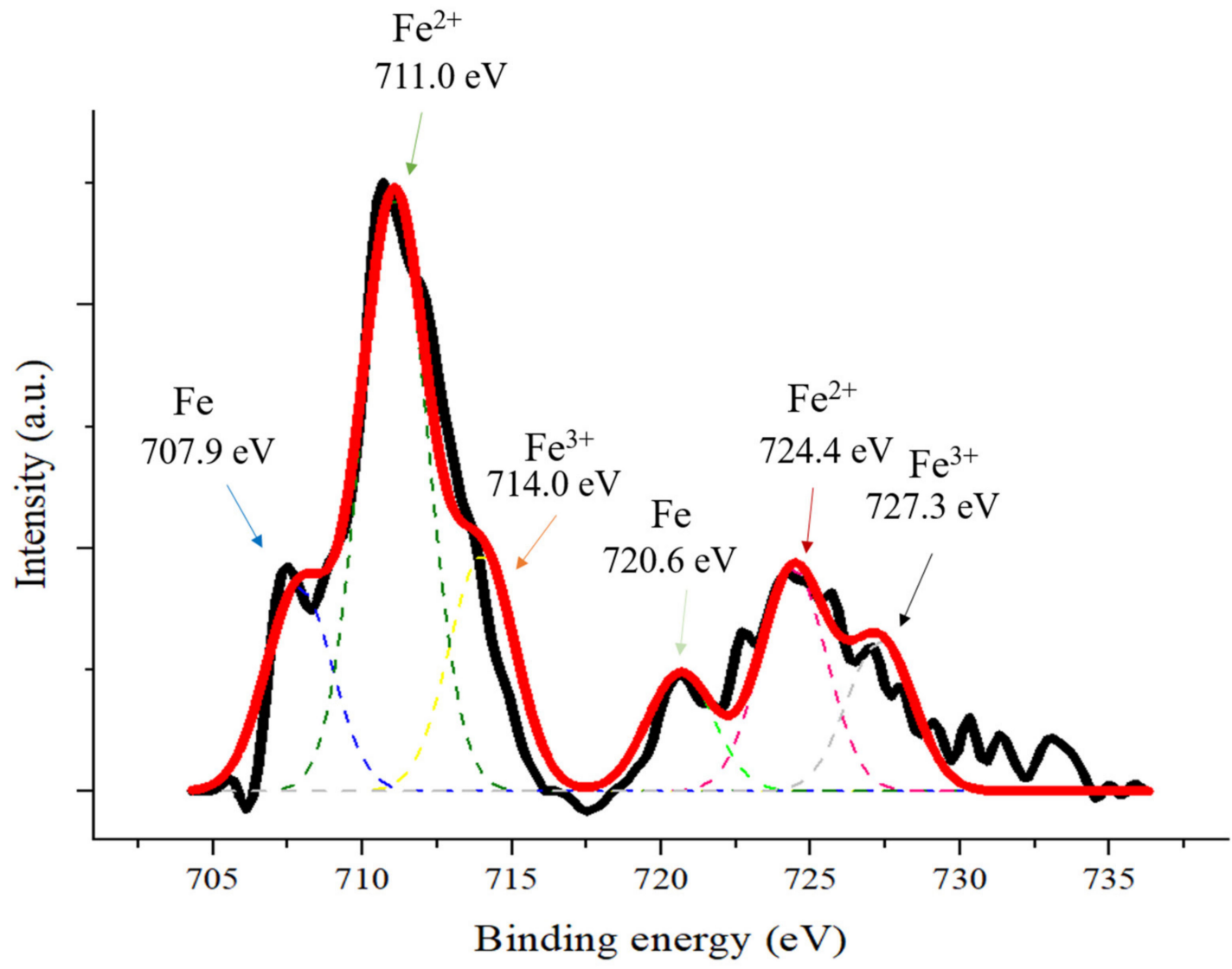

Figure 4. ESCA Fe-2p spectrum measured from CNTs grown on silicon, at $650{ }^{\circ} \mathrm{C}$, in a vapor mixture of ferrocene, camphor, water, and argon.

\subsection{Deposition of Nanocarbons on Silicon Flakes}

Thermal CVD of nanocarbons, including CNTs, on a planar wafer continuously is different from that on a pile of silicon flakes. There would be no nanocarbon coatings on silicon flakes which are buried under the top layer of silicon flakes. In this experiment, the container of silicon flakes was rotated, and individual silicon flake were exposed to the vapor of precursors briefly and for multiple times during the 15-min period. The coating on silicon flakes is a rapid thermal CVD process. Individual silicon flakes remain at the temperature of the CVD reactor but take turns to be exposed to the precursors for the growth of nanocarbons. The rapid thermal CVD time for individual silicon flakes is much shorter than the total period of the 15-min CVD process. Nuclei of CNTs on the surface of individual silicon flakes might not have adequate time to grow into long CNTs like those shown in Figure 3. By rotating the container of silicon flakes inside the CVD reactor, some fine silicon particles might remain floating and exposed to the precursors for a longer 
period of time. Long CNTs and some CFs would grow. Besides the rapid thermal CVD on individual silicon flakes, the surface morphology of silicon flakes is different from that of a polished, smooth and flat silicon wafer. Therefore, the actual nanocarbon coatings on silicon flakes might not be the same as that shown in Figure 3.

Water vapor has been reported to play a role of etching amorphous carbon that covered iron catalyst for it to remain active [41,42] for growing high-density CNTs. In the presence of water vapor and oxygen, iron was reported to oxidize at temperature below $500{ }^{\circ} \mathrm{C}$ [43]. The reactor was evacuated by a mechanical rotary pump. There were residual gases, including oxygen, in the reactor. Air in water in the water bubbler also supplied oxygen. Therefore, by the addition of water vapor to the thermal CVD of CNTs and graphitic nanocarbons, iron exposed to the CVD atmosphere is believed to be oxidized. Iron oxide has no adverse effects on the LIB operation. Metallic iron encapsulated by CNTs and graphitic carbons does not react with the electrolyte, either.

Unlike the aggregation of CNTs into a forest-like layer on a flat silicon waver, as shown in Figure 3, the nanocarbon CVD process causes nanocarbon-coated silicon flakes to aggregate into large particles. Figure 5A shows an SEM image of a cracked anode made of as-deposited silicon flakes. Ball milling of the nanocarbon-coated silicon flakes is necessary. Ball milling was carried out in ethanol, using a mixture of 5 and $10 \mathrm{~mm} \mathrm{ZrO}_{2}$ balls. After the ball milling, fine silicon flakes with nanocarbon coatings were obtained and are shown in the right bottle in Figure 6. Figure 5B shows an anode made of ball-milled silicon flakes with nanocarbon coatings exhibiting no cracks.
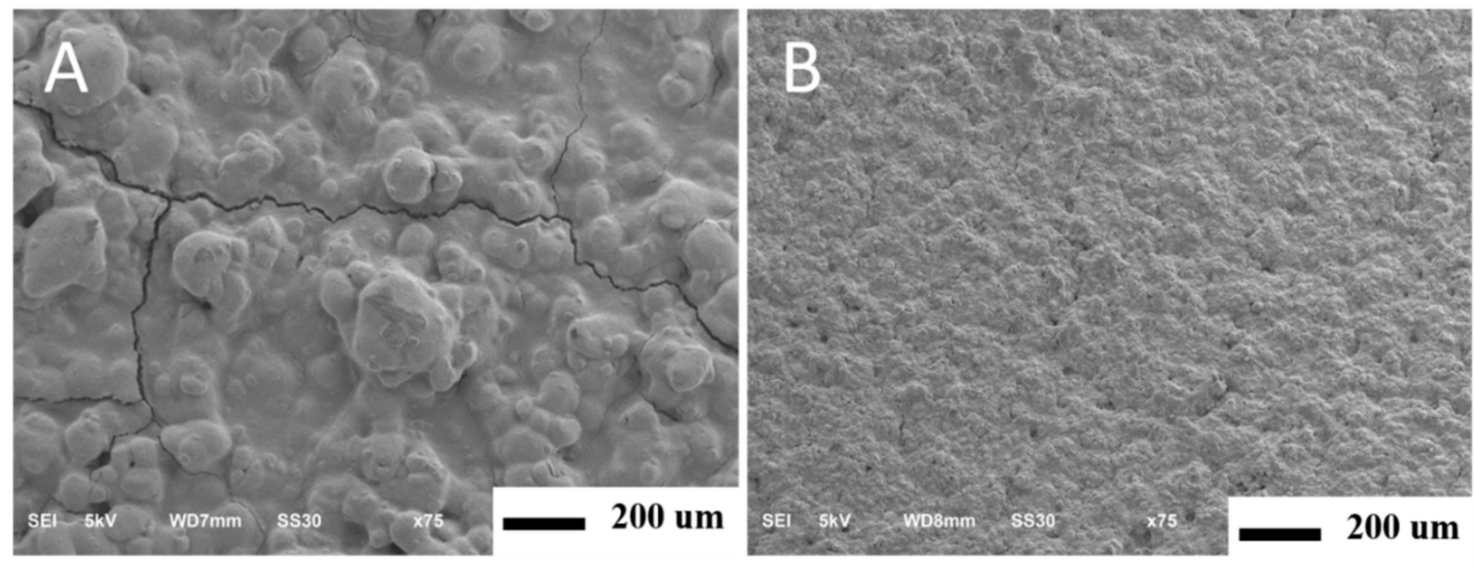

Figure 5. SEM images of anode made of silicon flakes with (A) nanocarbon coatings and (B) nanocarbon coats, followed by ball milling.
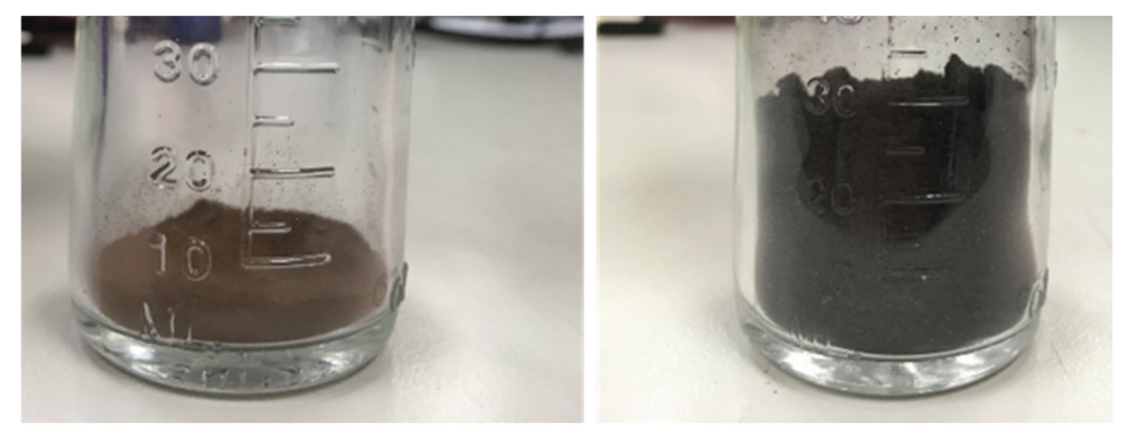

Figure 6. Photos of (left) as-received silicon flakes and (right) silicon flakes with graphitic nanocarbon coatings.

Figure 6 shows photos of pristine silicon flakes and nanocarbon-coated silicon flakes after ball milling. The left bottle contains the as-received silicon flakes. The right bottle contains nanocarbon coated silicon flakes after ball milling. The volume of the same 
amount of silicon flakes increases by about five times after the nanocarbon-coated silicon flakes are processed by ball milling. Although the total weight increases due to added carbon by only $10 \%$, the volume after ball milling increases by several times. Graphitic nanocarbon films, CNTs, and CFs on silicon flakes help keep silicon flakes apart and at a much larger distance than the as-received silicon flakes. Although the total volume of nanocarbon coated silicon flakes increases, after silicon flakes are mixed with binder and squeezed by a doctor blade to form a thick-film anode, CNTs and CFs yield to the applied pressure, and the anode volume is determined mainly by how silicon flakes stack to form a film. When thin and flat silicon flakes randomly stack to form the anode, two or more silicon flakes form a void, because, very possibly, they are not parallel to each other. The voids provide room for silicon flakes to expand in volume when lithium-silicon alloys form during lithiation. Far-reaching CNTs and CFs fill these voids and provide additional electrical connections between silicon flakes. Therefore, coarse and light nanocarbons, such as CNTs and CFs, are desirable for the anode of LIB. CNTs and CFs not only provide additional multiple electrical connections between the silicon and the current collector but also reserve room between silicon flakes, for them to expand in volume during the lithiation process. Even when a silicon flake breaks into multiple pieces, smaller pieces are enclosed by sponge-like CNTs and CFs nanostructure. Branching of CNTs and CFs is promoted due to the continuous supply of catalytic iron from decomposing ferrocene vapor. Catalytic iron deposits on CNTs and CFs cause additional CNTs and CFs to grow. Broken silicon pieces inside a network of CNTs and CFs retain a portion of electrical conductivity with the current collector. Some broken silicon pieces might retain the original CNTs and CFs deposited on a part of the surface. With the CNTs and CFs, the broken silicon flakes preserve their charging-and-discharging capability. Therefore, the cycling lifetime is expected to be improved in comparison with the as-received silicon flakes.

Figure 7 shows SEM images and the corresponding Raman spectra of as-received and nanocarbons coated silicon flakes. The images of silicon flakes are shown in Figure 7A. The Raman spectrum displays a sharp silicon Raman peak. At the reaction chamber temperature of $850{ }^{\circ} \mathrm{C}$, nanocarbons deposit on both surfaces of silicon flakes and the interior wall surface of the quartz tubing thermal CVD system. Carbon nanotubes, carbon nanofibers, and other phases of nanocarbons are deposited on both silicon flakes and the interior wall surface of the thermal CVD reactor. Based on Raman scattering and SEM images in Figure 7C, CNT-like and CF-like nanostructures are also deposited. The smooth surface of as-received silicon flakes is coated with nanocarbons of various thickness, exhibiting a rough morphology. The corresponding Raman spectrum shown in Figure 7D displays a sharp silicon peak and characteristic D-band $\left(\sim 1350 \mathrm{~cm}^{-1}\right)$, G-band $\left(\sim 1590 \mathrm{~cm}^{-1}\right)$, and 2D-band $\left(2700 \mathrm{~cm}^{-1}\right)$ of graphitic nanocarbons, including CNTs and CFs. The strong Raman G-band and 2D-band indicate that the nanocarbon coating is highly graphitic. Carbon coatings on the interior wall of the quartz tube reactor are not desirable. Therefore, a lower deposition temperature for effective deposition of conductive graphitic carbon phases on silicon flakes, while maintaining a clean and transparent quartz tube reactor, is selected.

Figure 7E shows graphitic carbons including CNTs and CFs deposit at $650{ }^{\circ} \mathrm{C}$ effectively on silicon flakes but not on quartz surface. On the surface of silicon flakes, a high density of carbon nanoparticles deposited. The inset in Figure 7E is an enlarged image of the surface of a silicon flake. Many particle-like deposits appear on the surface. Because of the short time period of CVD at a low temperature, there might not be adequate time for some iron catalytic nucleation of CNTs and CFs to grow into long and one-dimensional nanostructures. The graphitic-carbon-enclosed iron appears like nanoparticles on silicon flakes. An iron catalyst is important for the nanocarbon particles to be graphitic and electrically conductive. Although there are no direct evidences, we believe that exposed iron is oxidized at the reactor temperature of $650{ }^{\circ} \mathrm{C}$, in the environment of water vapor. Shown in Figure 7F is a Raman spectrum measured from silicon flakes after nanocarbon coating at $650{ }^{\circ} \mathrm{C}$. The sharp and strong Raman G-band indicates that carbon deposition 
at $650{ }^{\circ} \mathrm{C}$ is highly graphitic. Unlike a significant carbon coating at $850{ }^{\circ} \mathrm{C}$ on the interior wall of a quartz reactor, at $650{ }^{\circ} \mathrm{C}$ the quartz tubing reactor remains clear after nanocarbon deposition. This is more desirable because of less maintenance of the reactor.
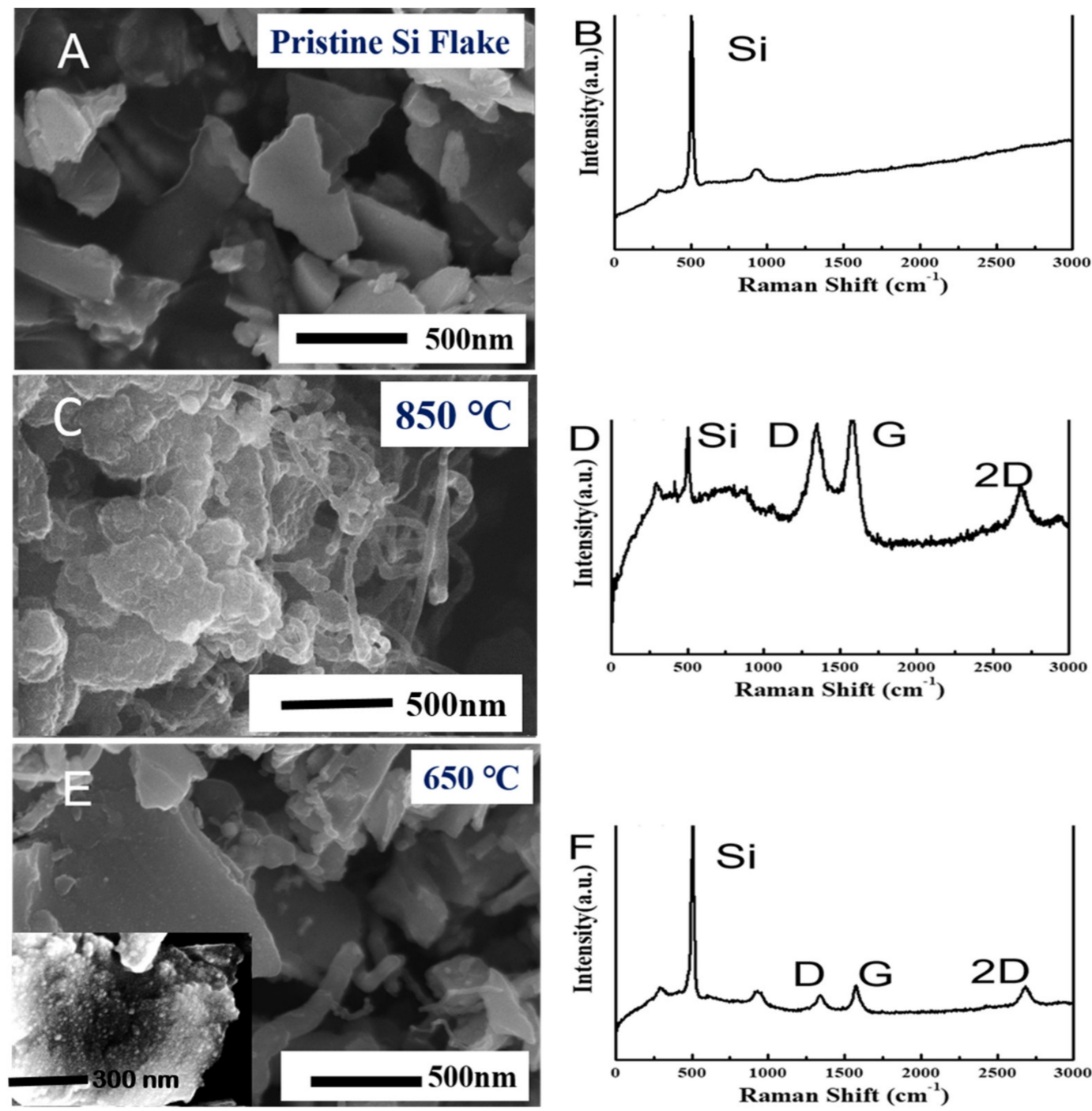

Figure 7. SEM images of silicon flakes $(\mathbf{A})$ as received, $(\mathbf{C})$ after nanocarbon coating at $850{ }^{\circ} \mathrm{C}$, and (E) after nanocarbon coating at $650{ }^{\circ} \mathrm{C}$. Corresponding Raman spectra of silicon flakes (B) as received, (D) after nanocarbon coating at $850{ }^{\circ} \mathrm{C}$, and (F) after nanocarbon coating at $650{ }^{\circ} \mathrm{C}$. The inset in $(\mathbf{E})$ is an enlarged image of the surface of a silicon flake.

Figure 8 shows EDX spectra of as-received silicon flakes and silicon flakes having been coated with CNTs, CFs, and graphitic carbon nanoparticles. Besides silicon, carbon, and oxygen, a significant amount of iron is shown to be on the nanocarbon-coated silicon flakes. Metallic iron is not desirable in LIB anodes. The addition of water vapor in the thermal CVD process resolves this issue. Most iron is embedded inside CNTs and CFs. Exposed iron is oxidized to form iron oxides. The amount of iron oxide and its contribution to the capacity is small. Nevertheless, the oxidization of iron prevents complications which metallic iron may cause to the long-term stability of repetitive charging and discharging of the silicon-flake-based anode [44-47]. 


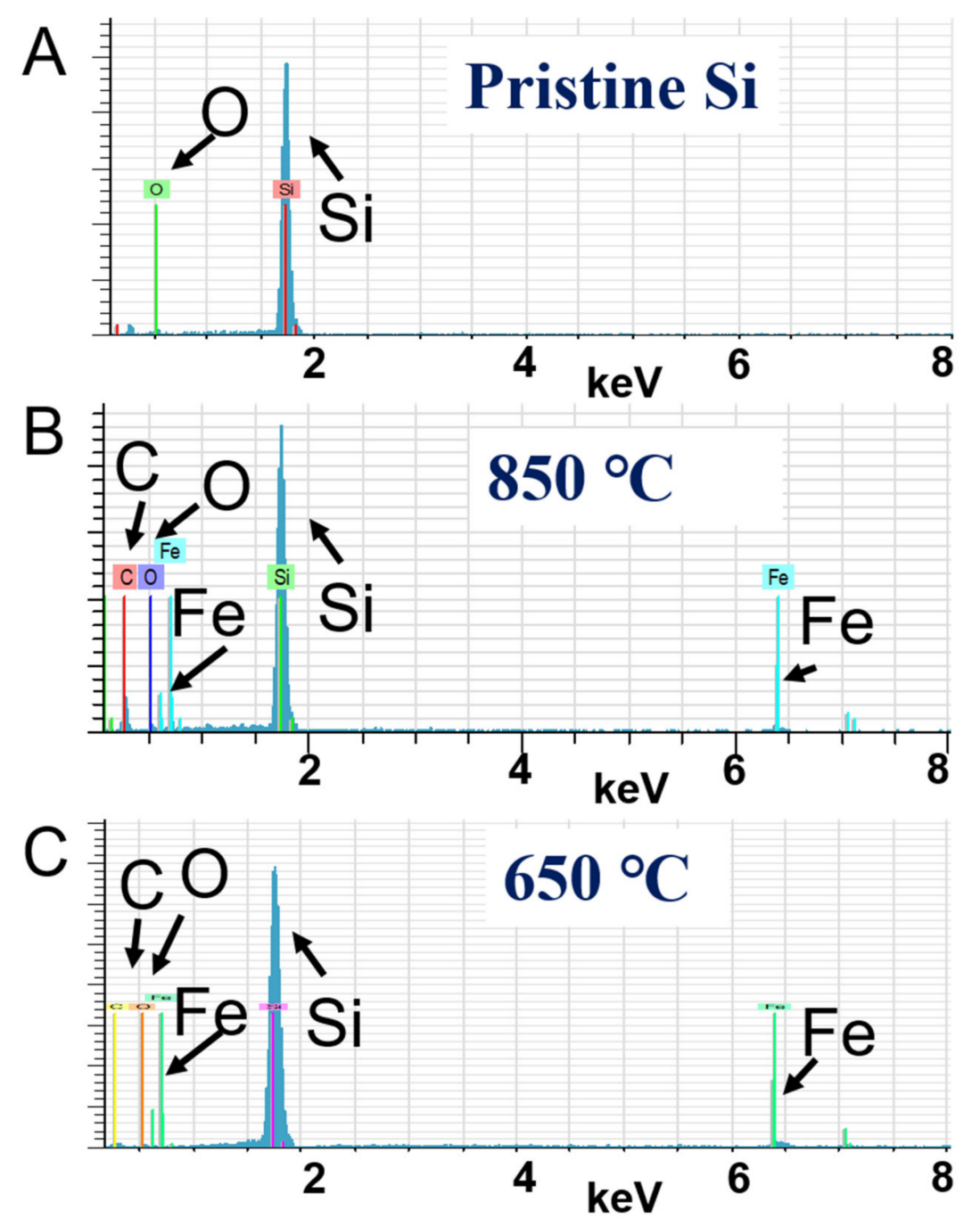

Figure 8. EDAX spectra of (A) as-received silicon flakes and those coated by CNTs and nanocarbons, using ferrocene and camphor in water vapor at (B) $850{ }^{\circ} \mathrm{C}$ and (C) $650{ }^{\circ} \mathrm{C}$.

\subsection{Lithiation and Delithiation of Nanocarbon Coated Silicon Flakes}

Figure 9 shows cyclic voltammetry analysis of the first three cycles of lithiation and delithiation processes for as-received silicon flakes and silicon flakes having been coated with nanocarbons. The cyclic voltammetry equipment and methods of measurement and analysis are reported in detail in [20]. Figure 9A shows the CV curves for the first three cycles of the anode made of as-received silicon flakes without nanocarbon coatings. The lithiation of crystalline silicon occurs at $0.0 \mathrm{~V}$ and converts crystalline silicon into amorphous lithium-silicon alloys. The subsequent delithiation of lithium-silicon alloys does not cause silicon to re-crystallize, but, instead, silicon remains amorphous. The subsequent lithiation of amorphous silicon beginning from the second cycle occurs near $0.2 \mathrm{~V}$. The peak near $0.6 \mathrm{~V}$ shows the delithiation of the anode made of as-received silicon flakes without nanocarbon coatings. The lithium-silicon alloys dissociate to release lithium ions into the electrolyte $[48,49]$. The delithiation of lithium-silicon alloys results in amorphous silicon. Due to poor conductivity of as-received silicon flakes, the peak currents shown in Figure $9 \mathrm{~A}$ are low. 

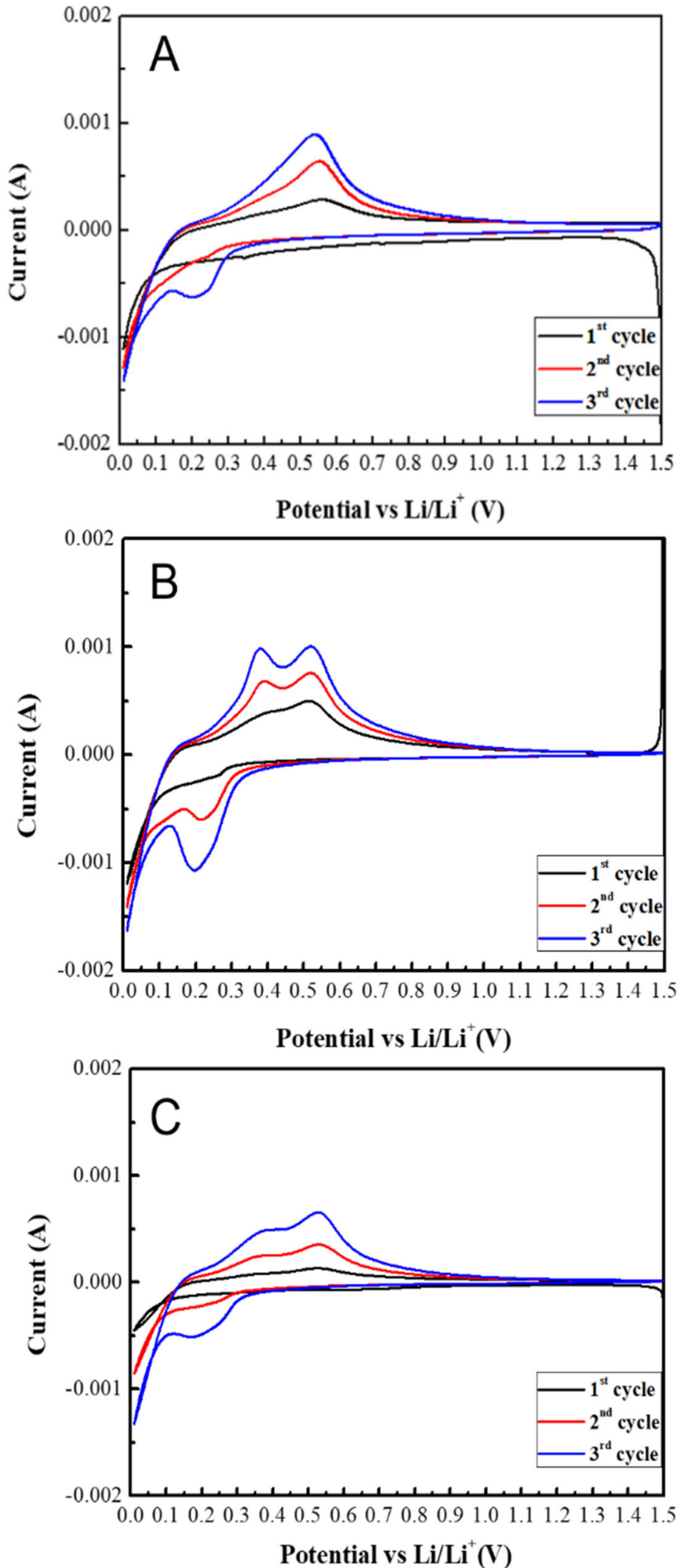

Figure 9. Cyclic voltammetry traces of anode made of $(\mathbf{A})$ as-received silicon flakes, $(\mathbf{B})$ silicon flakes after nanocarbon coating at $850^{\circ} \mathrm{C}$, and (C) silicon flakes after nanocarbon coating at $650{ }^{\circ} \mathrm{C}$. 
Figure 9B shows CV curves of an anode made of silicon flakes after nanocarbon coating at $850{ }^{\circ} \mathrm{C}$ in water vapor. With conductive graphitic carbon on silicon flakes, the peak currents shown in Figure 9B are larger than anode made of as-received silicon flakes shown in Figure 9A. The lithiation of silicon occurs at $0.0 \mathrm{~V}$ initially and then at near $0.2 \mathrm{~V}$ when crystalline silicon converts to amorphous silicon. Besides the delithiation peak near $0.6 \mathrm{~V}$ shown in Figure 9A for as-received silicon flakes, there is an additional delithiation peak near $0.4 \mathrm{~V}$. This is attributed to delithiation to an intermediate $\mathrm{Li}-\mathrm{Si}$ phase first and then full delithiation to amorphous $\mathrm{Si}$ [50-52].

Figure $9 \mathrm{C}$ shows $\mathrm{CV}$ curves of an anode made of silicon flakes after nanocarbon coating at $650{ }^{\circ} \mathrm{C}$. The CV curves appear similar to those in Figure 9B, except with slightly lower peak currents. Compared to nanocarbon coating at a higher temperature of $850^{\circ} \mathrm{C}$, a thinner silicon dioxide forms at $650{ }^{\circ} \mathrm{C}$ between the nanocarbon coating and silicon. The ratio of the delithiation peak at $0.4 \mathrm{~V}$ to that at $0.6 \mathrm{~V}$ is smaller. The lower current is also attributed to less nanocarbon deposition and lower conductivity due to low temperature deposition of nanocarbons at $650{ }^{\circ} \mathrm{C}$. Because the charge storage capacity of carbon is much less than that of silicon, too much carbon deposition on silicon flakes is not desirable in terms of the achievable as high as possible per weight specific capacity of the anode.

\subsection{Effects of Nanocarbon Coatings on Cycling Performance}

Figure 10 shows the comparison of cycling performance between anodes made of asreceived silicon flakes and those made of nanocarbon coated silicon flakes. The discharging cutoff potential is $10 \mathrm{mV}$. The charging cutoff potential is $1.5 \mathrm{~V}$. Cycling performance of silicon-flake-based anode is compared between different anodes by repetitive discharging and charging up to a preset maximum lithiation capacity following by delithiation. The discharging/charging rate is $0.01 \mathrm{C}$ for the first three cycles and $0.1 \mathrm{C}$ for remaining cycles. Controlling the maximum lithiation and delithiation level can be realized by power management integrated circuits. Figure $10 \mathrm{~A}$ shows that an anode made of as-received silicon as the active media survives for 20 cycles for a preset capacity of $1600 \mathrm{mAh} / \mathrm{g}$ before rapid decay in capacity. Figure 10B shows that the same anode shown in Figure 10A survives for only about 10 cycles for a preset capacity of $2000 \mathrm{mAh} / \mathrm{g}$. For the anode made of nanocarbon coated silicon flakes, at both 1600 and $2000 \mathrm{mAh} / \mathrm{g}$ capacity, the anode retains the preset capacity for 100 cycles. This comparison clearly demonstrates the high effectiveness of the nanocarbon coating process.

The thin and flat shape of silicon flakes naturally stack randomly in an anode, to leave abundant pores between neighboring silicon flakes, which are not parallel to each other. This is beneficial to silicon-based anode because these pores preserve room for the up to $400 \%$ volume expansion of silicon flakes when they become lithiated. CNTs and CFs fill the pores to provide multiple electrical connections between silicon flakes. The nanocarbon films on silicon flakes provides electrical conductivity of the silicon flakes for uniform lithiation and delithiation. Local stress forms due to differential volume expansion, which may cause a silicon flake to break into multiple smaller pieces. Some of these smaller pieces include fresh silicon surfaces without nanocarbon coatings. If a broken silicon flake loses all electrical connections to the current collector, its charge-and-discharge capacity is lost, too. The mass loading of the nanocarbon-coated silicon-flake-based anode is about $1 \mathrm{mg} / \mathrm{cm}^{2}$ with a density of $0.722 \mathrm{~g} / \mathrm{cm}^{3}$ excluding the current collector.

\subsection{Cycling Performance without Preset Maximum Capacity}

Figure 11 shows cycling performance of anodes made of as-received silicon flakes and silicon flakes with nanocarbon coatings at 850 and $650^{\circ} \mathrm{C}$. Unlike cycling with preset maximum capacity, this set of cycling evaluation allows test cells to discharge (lithiation) to the maximum above $2000 \mathrm{mAh} / \mathrm{g}$ capacity. During the first 10 cycles or so, the anode made of as-received silicon flakes is severely damaged by the large volume changes by high-capacity discharge and charge. The capacity rapidly deteriorates after the anode is damaged. The anode made of silicon flakes with nanocarbon coatings at $850{ }^{\circ} \mathrm{C}$ exhibits 
higher capacity during the first 15 cycles than that with nanocarbon coatings at $650{ }^{\circ} \mathrm{C}$. This is attributed to the higher conductance of nanocarbon coatings at 850 than $650{ }^{\circ} \mathrm{C}$. The higher the cycling capacity is, the more damages there will be, due to more severe volume changes of silicon flakes at a high capacity. The anode with nanocarbon coatings survive cycling for more than 40 times, at a capacity above $2250 \mathrm{mAh} / \mathrm{g}$, and then damages to the anode begin to adversely affect the cycling capacity. The damages shown by the blue curve do not occur when the cycling capacity is limited to the maximum of $2000 \mathrm{mAh} / \mathrm{g}$. When the lithiation of a silicon-based anode is limited so that the volume change of the anode does not cause pulverization of silicon, the silicon-based anode would sustain a long cycling life with excellent capacity retention. The maximum allowed lithiation level depends on the physical strength of the silicon-containing active material structure. This is the first challenge discussed in the introduction section related to the slowing down or prevention of silicon particles from breaking apart or even pulverizing [40]. The conductive nanocarbon coatings in this work help deal with the second challenge of maintaining the electrical contacts of silicon with the current collector of the anode. Power management of LIB with preset maximum capacity is feasible. However, when silicon is a minority active media of the anode and the other media forces silicon to reach its unlimited maximum first, the preset maximum capacity might not help. In that case, silicon discharges first to its maximum capacity, exceeding the capacity that silicon can tolerate, and the volumeexpansion-induced damages are difficult to prevent.
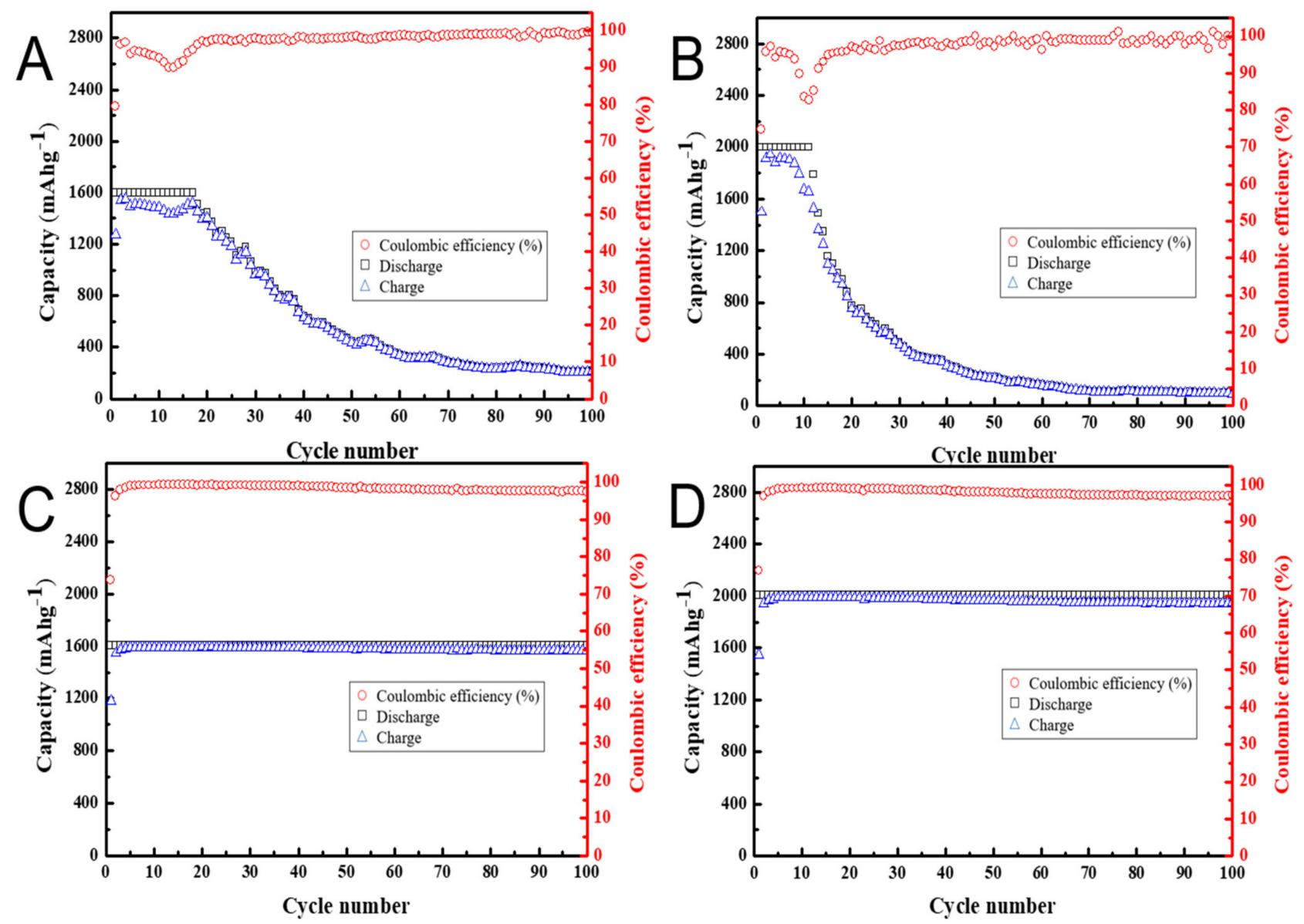

Figure 10. Cycling performance at the maximum lithiation (discharge) capacity of (A,C) $1600 \mathrm{mAh} / \mathrm{g}$ and (B,D) $2000 \mathrm{mAh} / \mathrm{g}$ for anodes made of $(\mathbf{A}, \mathbf{B})$ as-received silicon flakes and (C,D) nanocarbon-coated silicon flakes at $650{ }^{\circ} \mathrm{C}$. The discharging/charging rate is $0.01 \mathrm{C}$ for the first three cycles and $0.1 \mathrm{C}$ for remaining cycles. Only the weight of silicon is included in the calculation of the specific capacity. 


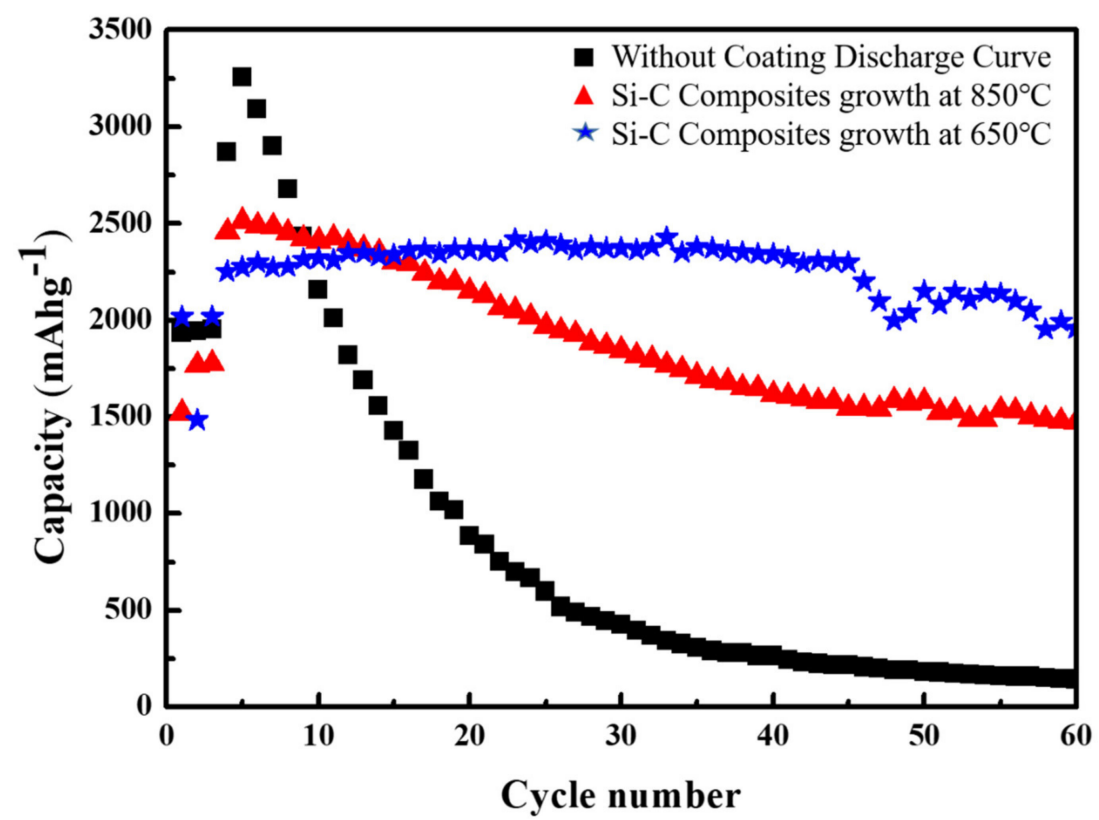

Figure 11. Comparison of cycling performance of lithium ion battery (LIB) anodes made of (black curve) as-received silicon flakes, (red curve) silicon flakes with nanocarbon coating at $850{ }^{\circ} \mathrm{C}$, and (blue curve) silicon flakes with nanocarbon coating at $650{ }^{\circ} \mathrm{C}$. The discharging/charging rate is $0.01 \mathrm{C}$ for the first three cycles and $0.1 \mathrm{C}$ for remaining cycles.

\subsection{Effects of Discharging-Charging Rates}

Figure 12 shows the cycling performance of anode based on silicon flakes with nanocarbon coatings at $650{ }^{\circ} \mathrm{C}$. The maximum capacity is set at $1600 \mathrm{mAh} / \mathrm{g}$. When the discharging-charging rate increases from 0.02 to $2 \mathrm{C}$, the capacity decreases some. When the discharging-charging rate decreases from $2 \mathrm{C}$, the capacity increases to about the previous level at the same rate. The Coulombic efficiency varies mostly between $99 \%$ and nearly $100 \%$. This shows the excellent durability and Coulombic coefficient of the nanocarbon coated silicon-flake-based anode under the cycling conditions.

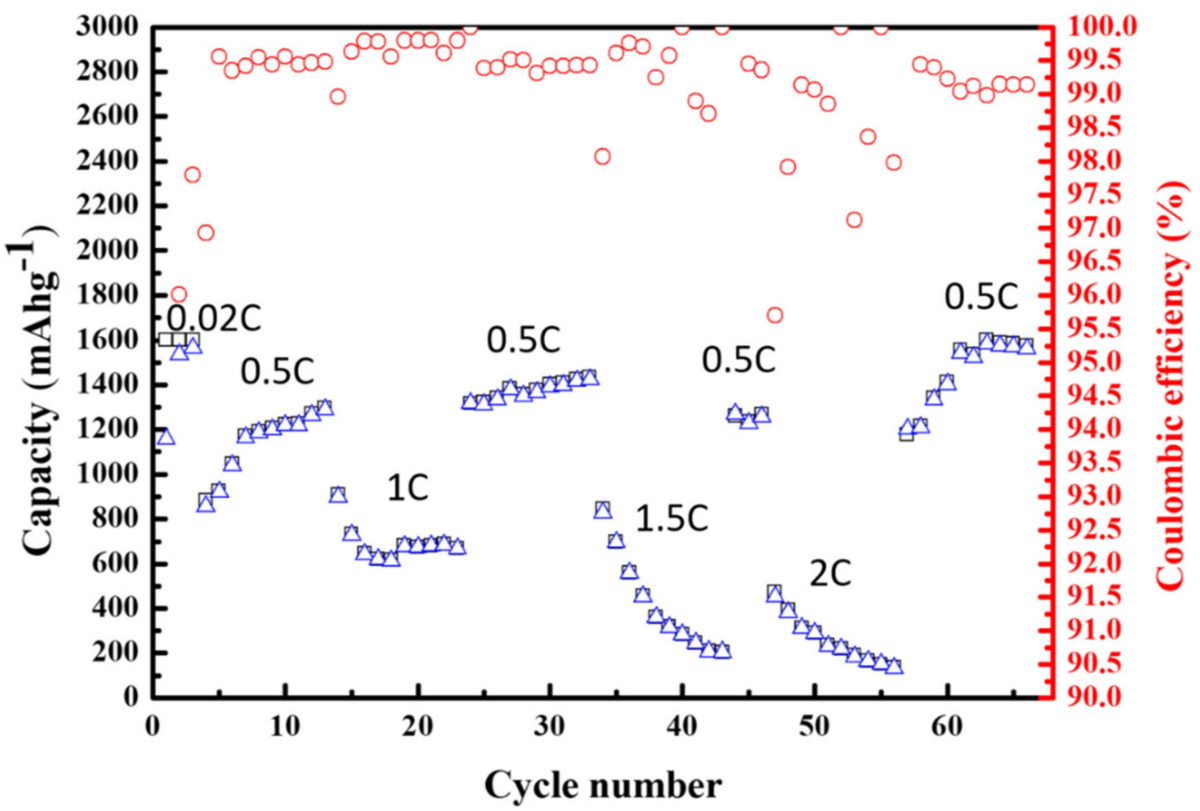

Figure 12. Cycling performance of a LIB half-cell with an anode made of silicon flakes coated with nanocarbons at $650{ }^{\circ} \mathrm{C}$. Discharging-charging rate varies from 0.02 to $2 \mathrm{C}$. 


\subsection{Effects of Nanocarbon on Anode Surface before and after Cycling}

Figure 13 shows SEM images, which compare LIB anodes made of as-received silicon flakes and those made of nanocarbon coated silicon flakes before and after cycling for 100 cycles. Figure 13A shows the surface of an anode made of as-received silicon flakes before cycling. Silicon flakes can vaguely be seen. Figure 13C shows the surface of an anode made of nanocarbon-coated silicon flakes. With nanocarbons, especially those long and far-reaching one-dimensional CNTs and CFs interconnecting neighboring silicon flakes, the anode surface appears less porous when compared with that in Figure 13A. After cycling for 100 cycles, Figure 13B shows that voids and cracks formed in the anode made of as-received silicon flakes. On the contrast, Figure 13D shows that the surface of anode made of nanocarbon coated silicon flakes retains its physical integrity very well. No significant cracks and voids appear on the surface. Instead, the surface after cycling is smooth and featureless.

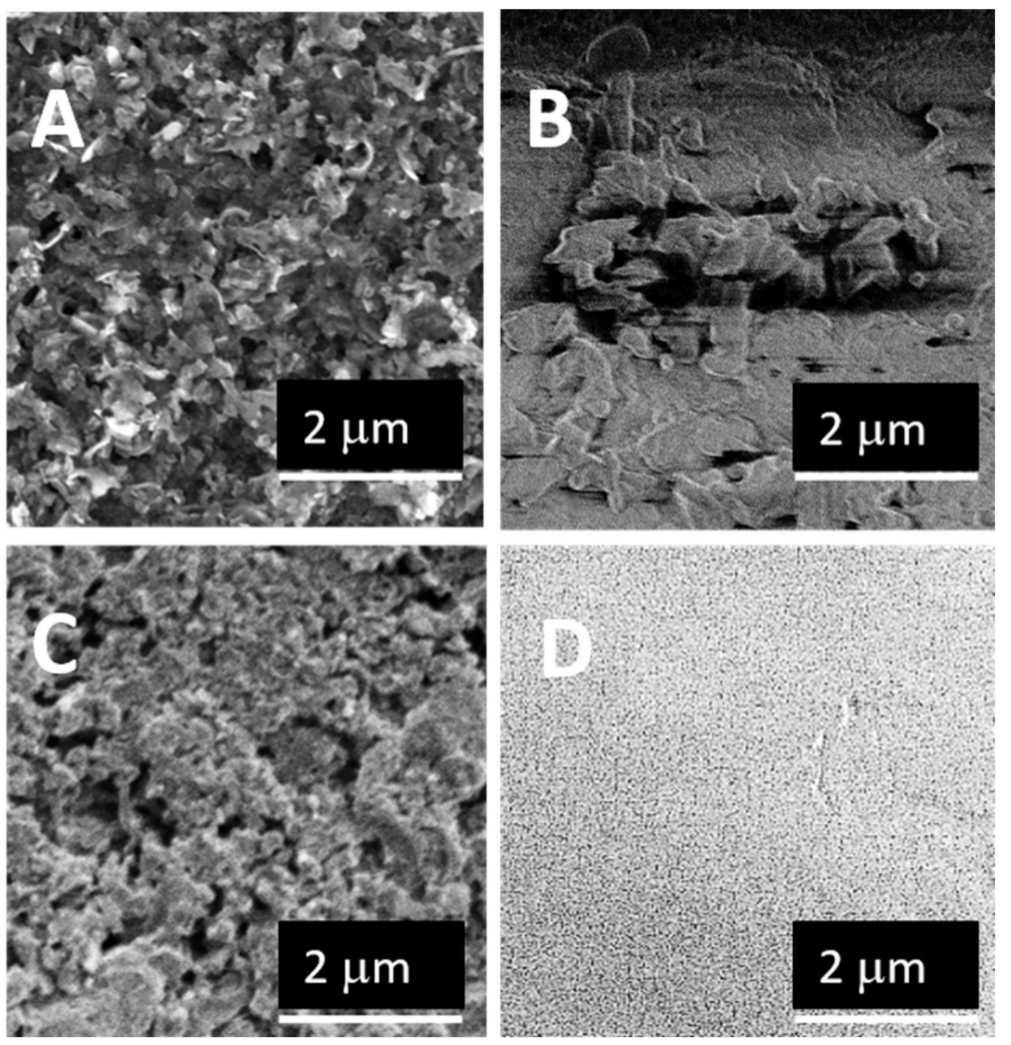

Figure 13. SEM images of anode surfaces (A,C) before and (B,D) after 100 cycles of discharging and charging. The anodes are made of $(\mathbf{A}, \mathbf{B})$ as-received silicon flakes and $(\mathbf{C}, \mathbf{D})$ silicon flakes coated with nanocarbons at $650{ }^{\circ} \mathrm{C}$.

\subsection{Effects of Conductivity Enhancing Additives}

The intrinsic conductivity of silicon-based anode is not as high as desired, due to the low conductivity of silicon and native oxide grown on silicon. Conductivity-enhancing agents, such as carbon black, are usually added with the binder and the silicon containing active media for the fabrication of silicon-based anode. With highly conductive graphitic nanocarbons on silicon flakes, additional conductivity-enhancing additives might not be needed any more.

Figure 14 shows cycling performance of nanocarbon coated silicon-based anode coated with nanocarbons at $650{ }^{\circ} \mathrm{C}$ and $(\mathrm{A}-\mathrm{C})$ without and (D-F) with Super-P conductivity enhancing agent. The cycling performance is compared at fixed discharging and charging levels of (A,D) $1200 \mathrm{mAh} / \mathrm{g}$, (B,E) $1600 \mathrm{mAh} / \mathrm{g}$, and (C,F) $2000 \mathrm{mAh} / \mathrm{g}$. The lithiation is carried out until a preset capacity is reached. The delithiation process then follows. Three 
capacity levels, i.e., 1200, 1600, and $2000 \mathrm{mAh} / \mathrm{g}$, are compared. Figure 14 shows that the addition of up to $20 \%$ by weight of Super-P makes no difference in the cycling performance in comparison with the anode made of nanocarbon coated silicon flakes without Super-P carbon black additive. The discharging/charging rate is $0.01 \mathrm{C}$ for the first three cycles and $0.1 \mathrm{C}$ for remaining cycles.
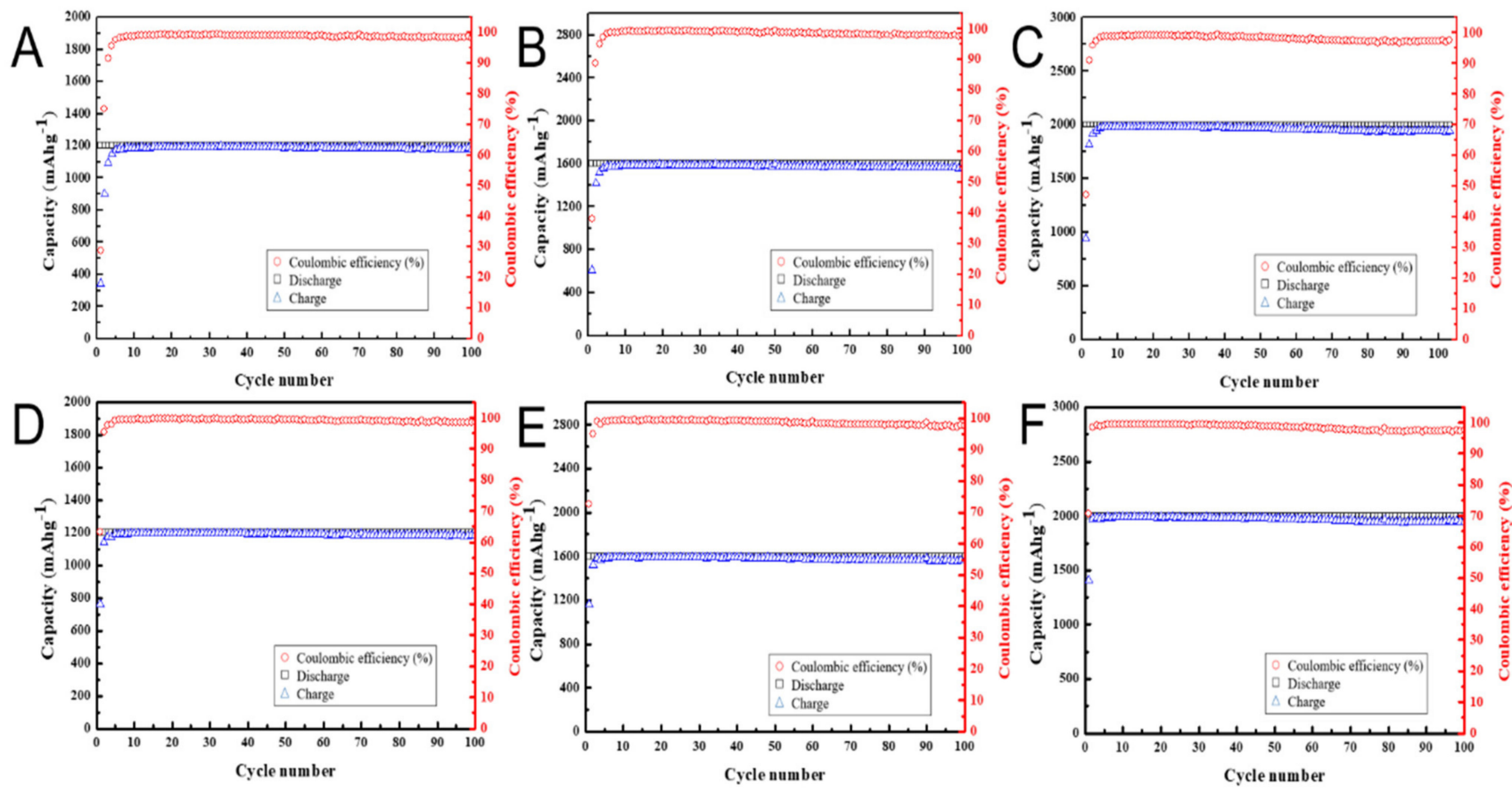

Figure 14. Cycling performance of nanocarbon-coated $\left(650^{\circ} \mathrm{C}\right)$ silicon-based anode $(\mathbf{A}-\mathrm{C})$ without and (D-F) with Super-P conductivity enhancing agent. The cycling performance is compared at fixed discharging and charging levels of (A,D) $1200 \mathrm{mAh} / \mathrm{g}$, (B,E) $1600 \mathrm{mAh} / \mathrm{g}$, and (C,F) $2000 \mathrm{mAh} / \mathrm{g}$. The discharging/charging rate is $0.01 \mathrm{C}$ for the first three cycles and $0.1 \mathrm{C}$ for remaining cycles.

\section{Conclusions}

Inexpensive silicon flakes obtained from waste by-products of silicon-wafer manufacturing processes exhibit high performance as an anode-active medium for lithium ion batteries. Conductive graphitic nanocarbons were coated on silicon flakes, using ferrocene as a catalyst for the growth of graphitic nanocarbons, including CNTs and CFs. Silicon flakes were stirred by rotating the container in the reactor for uniform coatings, on the surface of all silicon flakes. Individual silicon flakes were exposed to the precursors only briefly. The rapid thermal CVD deposited more CNTs and CFs at 850 than $650{ }^{\circ} \mathrm{C}$. At $650{ }^{\circ} \mathrm{C}$, besides CNTs and CFs, nanoparticle-like graphitic carbon grew on silicon surface. Anodes made of mixtures of silicon flakes with nanocarbon coatings at both 650 and $850{ }^{\circ} \mathrm{C}$ with conductivity enhancing Super-P carbon black and sodium carboxymethyl cellulose (NaCMC) binder at weight ratios of 6:2:2 and 8:0:2, corresponding to that with and without Super P additive, respectively, achieved high capacity retention at $2000 \mathrm{mAh} / \mathrm{g}$, after 100 cycles of discharge/charge at a rate of $0.1 \mathrm{C}$.

Author Contributions: Conceptualization, Y.T.; validation, Y.T.; formal analysis, Y.T., W.-C.H., C.-Y.J. and Y.-H.W.; investigation, Y.T. and W.-C.H.; resources, Y.T.; data curation, Y.T. and W.-C.H.; writingoriginal draft preparation, Y.T. and W.-C.H.; writing-review and editing, Y.T., C.-Y.J. and Y.-H.W.; visualization, W.-C.H., Y.T., C.-Y.J. and Y.-H.W.; supervision, Y.T.; project administration, Y.T.; funding acquisition, Y.T. All authors have read and agreed to the published version of the manuscript. 
Funding: This research was funded by Ministry of Science and Technology in Taiwan, grant number 109-2221-E-006-124-, and the APC was funded by the Ministry of Science and Technology in Taiwan, grant number 109-2221-E-006-124-

Institutional Review Board Statement: Not applicable.

Informed Consent Statement: Not applicable.

Acknowledgments: The authors gratefully acknowledge the use of electron spectroscopy for chemical analysis (PHI-500), provided by the Instrument Center of National Cheng Kung University. The authors thank the instrument engineer, Jui-Chin Lee, for assisting us in operating the ESCA.

Conflicts of Interest: The authors declare no conflict of interest. The funders had no role in the design of the study; in the collection, analyses, or interpretation of data; in the writing of the manuscript; or in the decision to publish the results.

\section{References}

1. Chiang, Y.-M. Building a Better Battery. Science 2010, 330, 1485-1486. [CrossRef]

2. Armand, M.; Tarascon, J.-M. Building better batteries. Nature 2008, 451, 652-657. [CrossRef]

3. Bruce, P.G.; Freunberger, S.A.; Hardwick, L.J.; Tarascon, J.-M. Li-O 2 and Li-S batteries with high energy storage. Nat. Mater. 2011, 11, 19-229. [CrossRef]

4. Amine, K.; Kanno, R.; Tzeng, Y. Rechargeable Lithium Batteries and Beyond: Progress, Challenges, and Future Directions. MRS Bull. 2014, 39, 395-401. [CrossRef]

5. Jing Xie, J.; Lu, Y.-C. A retrospective on lithium-ion batteries. Nat. Commun. 2020, 11, 2499.

6. Whittingham, M.S. Lithium Batteries and Cathode Materials. Chem. Rev. 2004, 104, 4271-4302. [CrossRef]

7. Kovalenko, I.; Zdyrko, B.; Magasinski, A.; Hertzberg, B.; Milicev, Z. A major constituent of brown algae for use in high-capacity Li-ion batteries. Science 2011, 334, 75-79. [CrossRef]

8. Zhang, X.; Wang, D.; Qiu, X.; Ma, Y.; Kong, D.; Mullen, K.; Li, X.; Zhi, L. Stable high-capacity and high-rate silicon-based lithium battery anodes upon two-dimensional covalent encapsulation. Nat. Commun. 2020, 11, 3826. [CrossRef]

9. Ma, D.; Cao, Z.; Hu, A. Si-Based Anode Materials for Li-Ion Batteries: A Mini Review. Nano-Micro Lett. 2014, 6, 347-358. [CrossRef]

10. Chan, C.K.; Peng, H.; Liu, G.; Mcllwrath, K.; Zhang, X.F. High-performance lithium battery anodes using silicon nanowires. Nat. Nanotechnol. 2008, 3, 31-35. [CrossRef]

11. An, S.J.; Li, J.; Daniel, C.; Mohanty, D.; Nagpure, S.; Wood, D.L., III. The state of understanding of the lithium-ion-battery graphite solid electrolyte interphase (SEI) and its relationship to formation cycling. Carbon 2016, 105, 52-76. [CrossRef]

12. Li, Q.; Chen, J.; Fan, L.; Kong, X.; Lu, Y. Progress in electrolytes for rechargeable Li-based batteries and beyond. Green Energy Environ. 2016, 1, 18-42. [CrossRef]

13. Magasinski, A.; Dixon, P.; Hertzberg, B.; Kvit, A. High-performance lithium-ion anodes using a hierarchical bottom-up approach. Nat. Mater. 2010, 9, 353-358. [CrossRef]

14. Dahn, J.R.; Zheng, T.; Liu, Y.; Xue, J.S. Mechanisms for Lithium Insertion in Carbonaceous Materials. Science 1995, $270,590-593$. [CrossRef]

15. Terranova, M.L.; Orlanducci, S.; Tamburri, E.; Guglielmotti, V.; Rossi, M. Si/C hybrid nanostructures for Li-ion anodes: An overview. J. Power Sources 2014, 246, 167-177. [CrossRef]

16. Wang, B.; Li, X.; Qiu, T.; Luo, B.; Ning, J.; Li, J.; Zhang, X.; Liang, M.; Zhi, L. High Volumetric Capacity Silicon-Based Lithium Battery Anodes by Nanoscale System Engineering. Nano Lett. 2013, 13, 5578-5584. [CrossRef]

17. Ge, M.; Fang, X.; Rong, J.; Zhou, C. Review of porous silicon preparation and its application for lithium-ion battery anodes. Nanotechnology 2013, 24, 422001. [CrossRef]

18. Cho, J.-H.; Picraux, S.T. Enhanced Lithium Ion Battery Cycling of Silicon Nanowire Anodes by Template Growth to Eliminate Silicon Underlayer Islands. Nano Lett. 2013, 13, 5740. [CrossRef]

19. Tzeng, Y.; Chen, C.-A. Composite Electrode Material and Method for Manufacturing the Same. U.S. Patent \#10,411,253, 10 September 2019.

20. Pan, Y.-T.; Tzeng, Y. Silicon Nanoparticles in Graphene Sponge for Long-Cycling-Life and High-Capacity Anode of Lithium Ion Battery. IEEE Trans. Nanotechnol. 2019, 18, 1097-1102. [CrossRef]

21. Ge, M.; Rong, J.; Fang, X.; Zhou, C. Porous Doped Silicon Nanowires for Lithium Ion Battery Anode with Long Cycle Life. Nano Lett. 2012, 12, 2318-2323.

22. Chan, C.K.; Ruffo, R.; Hong, S.S.; Cui, Y. Surface chemistry and morphology of the solid electrolyte interphase on silicon nanowire lithium-ion battery anodes. J. Power Sources 2009, 1132, 189-1140. [CrossRef]

23. Liu, X.H.; Zhong, L.; Huang, S.; Mao, S.X.; Zhu, T.; Yu, J.; Liu, H. Size-Dependent Fracture of Silicon Nanoparticles During Lithiation. ACS Nano 2012, 6, 1522-1531. [CrossRef] [PubMed]

24. Roselin, L.S.; Juang, R.-S.; Hsieh, C.-T.; Sagadevan, S.; Umar, A.; Selvin, R.; Hegazy, H.H. Recent Advances and Perspectives of Carbon-Based Nanostructures as Anode Materials for Li-ion Batteries. Materials 2019, 12, 1229. [CrossRef] [PubMed] 
25. Wong, D.P.; Tseng, H.-P.; Chen, Y.-T.; Hwang, B.-J.; Chen, L.C.; Chen, K.-H. A stable silicon/graphene composite using solvent exchange method as anode materialfor lithium ion batteries. Carbon 2013, 63, 397-403. [CrossRef]

26. Xu, B.; Lin, C.X.; Wang, B.; Zhang, Z.; Zhao, X.S. Stablilization of silicon nanoparticles in graphene aerogel framework for lithium ion storage. RSC Adv. 2015, 5, 30624. [CrossRef]

27. Ikonen, T.; Kalidas, N.; Lahtinen, K.; Isoniemi, T.; Toppari, J.J.; Vazquez, E.; Herrero-Chamorro, M.A.M.; Fierro, J.L.G.; Kallio, T.; Lehto, V.-P. Conjugation with carbon nanotubes improves the performance of mesoporous silicon as Li-ion battery anode. Sci. Rep. 2020, 10, 5589. [CrossRef]

28. Li, X.; Zhang, G.; Zhang, L.; Zhong, M.; Yuan, X. Silicon/Graphite/Carbon Nanotubes Composites as Anode for Lithium Ion Battery. Int. J. Electrochem. Sci. 2015, 10, 2801-2811.

29. Ng, S.H.; Wang, J.; Wexler, D.; Chew, S.Y.; Liu, H.K. Amorphous Carbon-Coated Silicon Nanocomposites: A Low-Temperature Synthesis via Spray Pyrolysis and Their Application as High-Capacity Anodes for Lithium Ion Batteries. J. Phys. Chem. C 2007, 111, 11131-11138. [CrossRef]

30. Wu, J.; Cao, Y.; Zhao, H.; Mao, J.; Guo, Z. The critical role of carbon in marrying silicon and graphite anodes for high-energy lithium-ion batteries. Carbon Energy 2019, 1. [CrossRef]

31. Xiong, Z.; Yun, Y.S.; Jin, H.-J. Applications of Carbon Nanotubes for Lithium Ion Battery Anodes. Materials 2013, 6, 1138-1158. [CrossRef]

32. Cheng, Y.W.; Pandey, R.K.; Li, Y.C.; Chen, C.H.; Peng, B.L.; Huang, J.H.; Chen, Y.X.; Liu, C.P. Conducting nitrogen-incorporated ultrananocrystalline diamond coating for highly structural stable anode materials in lithium ion battery. Nano Energy 2020, 74, 104811. [CrossRef]

33. Cheng, Y.W.; Lin, C.-K.; Chu, Y.-C.; Abouimrane, A.; Chen, Z.; Ren, Y.; Liu, C.-P.; Tzeng, Y.; Auciello, O. Electrically conductive ultrananocrystalline diamond-coated natural graphite-copper anode for new long life lithium-ion battery. Adv. Mater. 2014, 26, 3724-3729. [CrossRef] [PubMed]

34. Kumar, M.; Ando, Y. Chemical vapor deposition of carbon nanotubes: A review on growth mechanism and mass production. J. Nanosci. Nanotechnol. 2010, 10, 3739-3758. [CrossRef] [PubMed]

35. Manawi, Y.M.; Ihsanullah, S.A.; Tareq, A.L.; Atieh, M.A. A review of carbon nanomaterials' synthesis via the chemical vapor deposition (CVD) method. Materials 2018, 11, 822. [CrossRef] [PubMed]

36. Dong, L.; Park, J.G.; Leonhardt, B.E.; Zhang, S.; Liang, R. Continuous Synthesis of Double-Walled Carbon Nanotubes with Water-Assisted Floating Catalyst Chemical Vapor Deposition. Nanomaterials 2020, 10, 365. [CrossRef] [PubMed]

37. Kim, K.; Kim, K.; Jung, W.S.; Bae, S.Y.; Park, J.; Choi, J.; Choo, J. Investigation on the temperature-dependent growth rate of carbon nanotubes using chemical vapor deposition of ferrocene and acetylene. Chem. Phys. Lett. 2005, 401, 459-464. [CrossRef]

38. Roy, S.; David-Pur, M.; Hanein, Y. Carbon nanotube growth inhibition in floating catalyst based chemical vapor deposition and its application in flexible circuit fabrication. Carbon 2017, 116, 40-49. [CrossRef]

39. Kumar, M.; Ando, Y. Controlling the diameter distribution of carbon nanotubes grown from camphor on a zeolite support. Carbon 2005, 43, 533-540. [CrossRef]

40. Tzeng, Y.; Chen, R.; He, J.-L. Silicon-Based Anode of Lithium Ion Battery Made of Nano Silicon Flakes Partially Encapsulated by Silicon Dioxide. Nanomaterials 2020, 10, 2467. [CrossRef]

41. Yamada, T.; Maigne, A.; Yudasak, M.; Mizuno, K.; Futaba, D.N.; Yumura, M.; Iijima, S.; Hata, K. Revealing the Secret of Water-Assisted Carbon Nanotube Synthesis by Microscopic Observation of the Interaction of Water on the Catalysts. Nano Lett. 2008, 8, 4288-4292. [CrossRef]

42. Cheng, Q.; Bao, J.; Park, J.G.; Liang, R.; Zhang, C.; Wang, B. High Mechanical Performance CompositeConductor: Multi-Walled Carbon Nanotube Sheet/Bismaleimide Nanocomposites. Adv. Funct. Mater. 2009, 19, 3219-3225. [CrossRef]

43. Bertrand, N.; Desgranges, C.; Poquillon, D.; Lafont, M.C.; Monceau, D. Iron Oxidation at Low Temperature (260-500 $\left.{ }^{\circ} \mathrm{C}\right)$ in Air and the Effect of Water Vapor. Oxid. Met. 2010, 73, 139-162. [CrossRef]

44. Zhang, L.; Wu, H.B.; Lou, X.W. Iron-Oxide-Based Advanced Anode Materials for lithium-Ion Batteries. Adv. Energy Mater. 2014, 4, 1300958. [CrossRef]

45. Wu, Q.; Jiang, R.; Mu, L.; $\mathrm{Xu}, \mathrm{S} . \mathrm{Fe}_{3} \mathrm{O}_{4}$ anodes for lithium batteries: Production techniques and general applications. C. R. Chim. 2019, 22, 96-102. [CrossRef]

46. Yoon, T.; Kim, J.; Kim, J.; Lee, J.K. Electrostatic Self-Assembly of $\mathrm{Fe}_{3} \mathrm{O}_{4}$ Nanoparticles on Graphene Oxides for High Capacity Lithium-Ion Battery Anodes. Energies 2013, 6, 4830-4840. [CrossRef]

47. Tang, J.; Lugo, C.E.Z.; Guzman, S.F.A.; Daniel, G.; Kessler, V.G.; Seisenbaeva, G.A.; Pol, V.G. Pushing the theoretical capacity limits of iron oxide anodes: Capacity rise of $\mathrm{g}-\mathrm{Fe}_{2} \mathrm{O}_{3}$ nanoparticles in lithium-ion batteries. Mater. Chem. A 2016, 46, 18107-18115. [CrossRef]

48. Jerliu, B.; Huger, E.; Dorrer, L.; Seidlhofer, B.K.; Steitz, R.; Horisberger, M.; Schmidt, H. Lithium insertion into silicon electrodes studied by cyclic voltammetry and operando neutron reflectometry. Phys. Chem. Chem. Phys. 2018, 20, 23480-23491. [CrossRef]

49. Zhang, X.; Qiu, X.; Kong, D.; Zhou, L.; Li, Z.; Li, X.; Zhi, L. Silicene Flowers: A Dual Stabilized Silicon Building Block for High-Performance Lithium Battery Anodes. ACS Nano 2017, 11, 7476-7484. [CrossRef]

50. Schroder, K.W.; Dylla, A.G.; Harris, S.J.; Webb, L.J.; Stevenson, K.J. Role of Surface Oxides in the Formation of Solid-Electrolyte Interphases at Silicon Electrodes for Lithium-Ion Batteries. ACS Appl. Mater. Interfaces 2014, 6, 21510-21524. [CrossRef] 
51. Schnabel, M.; Harvey, S.P.; Arca, E.; Stetson, C.; Teeter, G.; Ban, C.; Stradins, P. Surface $\mathrm{SiO}_{2}$ Thickness Controls Uniform-toLocalized Transition in Lithiation of Silicon Anodes for Lithium-Ion Batteries. ACS Appl. Mater. Interfaces 2020, 12, 27017-27028. [CrossRef]

52. Yu, S.; Lipovskikh, S.A.; Katorova, N.S.; Savina, A.A.; Abakumov, A.M.; Stevenson, K.J. Solid-electrolyte interphase nucleation and growth on carbonaceous negative electrodes for Li-ion batteries visualized with in situ atomic force microscopy. Sci. Rep. 2020, 10, 8550 . 